\title{
A Probe into the Combination of Heluo Martial Arts Culture and Modern Physical Education
}

\author{
Cheng Nan \\ Luoyang Normal College \\ Luoyang, Henan Province, China \\ chengnan1107@163.com
}

\begin{abstract}
As a country with a long history, martial arts culture has been inherited in China for at least hundreds of years. Today, martial arts culture is still one of the important intangible heritages, and has been correctly and reasonably maintained. But in order to integrate with the times, martial arts culture is difficult to be retained in a rut. Therefore, we must integrate modern factors into martial arts culture to maximize its own advantages and value. This article mainly aims to study how to combine Heluo martial arts culture with modern physical education perfectly through ways such as improving the teaching mode of martial arts class and the martial arts teaching quality of martial arts teachers, stimulating students' interest in martial arts, arranging targeted teaching content, focusing on the research of teaching methods, and improving the status of Heluo martial arts with corresponding policies, so as to give full play to their advantages and let martial arts culture be inherited in the interactive process of maintenance and innovation. In this process, try to arouse students' resonance, so that students can feel the physical and mental experience brought by martial arts culture, and immerse themselves in the wonderful martial arts culture, so as to enable students to learn traditional etiquette, improve classroom fun and interaction, achieve the expected effect of focusing on student development and paying attention to student's subject position.
\end{abstract}

Keywords-Heluo martial arts culture; modern physical education; combination; inheritance

\section{INTRODUCTION}

As one of the sources of Chinese civilization, Heluo culture plays an important role in national culture. At the same time, Heluo's martial arts culture, as an important part of Chinese martial arts culture, has made martial arts become an important carrier of national culture through the inheritance and development. The diversification of today's cultural form determines that martial arts can not exist simply as a sport project, or it will easily lead to derailment of martial arts culture from modern culture, and make it hard to progress and develop. The presenting process of martial arts is the infiltration and dissemination of culture. It can show the profound connotation of martial arts culture and its own value.[1] The learning and mastery of martial arts is not just to exercise. It is also a good way to relax and cultivate our moral character, so as to suit people's life demands. In order to better show Heluo martial arts culture to the world, we need to use new means and more convincing and appealing ways to let more people fall in love with this sport.

\section{Heluo Martial ARTS CUlture}

Heluo martial arts culture is mainly composed of two parts, namely the technical culture and literature and art culture of Heluo martial arts. Technical culture mainly refers to the list of Heluo martial arts, including Shaolin martial arts culture, Tai chi chuan martial arts culture, regimen martial arts culture.[2] The literature and art culture refers to local temple fairs in Heluo. Let more foreign tourists understand the martial arts culture in Heluo area through these tourism activities.

\section{A. The Technical Culture of Heluo Martial Arts}

With the gradual development of Heluo martial arts, the martial arts system, which is represented by Shaolin boxing, Tai chi chuan and Changjia boxing, has been gradually formed. The various boxing technologies have formed rich technical culture of Heluo martial arts. The distribution of each boxing school is different:

Luoyang: Shaolin boxing; Tai chi chuan; Nanwu boxing; Tongbei boxing (Simianbafang tongbei boxing, Song tongbei boxing); Luoyang Xinyi Liuhe boxing; Mudan boxing; Changjia boxing; Cha boxing; monkey boxing; Meihua boxing; Tan boxing; Hong Boxing; Tangping boxing; Yi boxing (Dacheng boxing); Baji boxing; Hong boxing; Mulan boxing; Wudang boxing; Liupan Zashi boxing.

Yanshi: Shaolin boxing; Tai chi chuan; Nanwu boxin; Tongbei boxing (Song tongbei boxing); Changjia boxing; Cha boxing; Bagua boxing; Liupan Zashi boxing; Hong boxing; Tangping boxing; Yi boxing (Dacheng boxing); Guiji boxing.

Luoning: Shaolin boxing; Tai chi chuan; Changjia boxing; Xinyi boxing; Meihua boxing.

Mengjin: Shaolin boxing; Tai chi chuan; Xinyi boxing; Bagua boxing; Zhongyi boxing; Yi boxing (Dacheng boxing); Tongbei boxing.

Xuanyang: Tai chi chuan; Xinyi boxing; Bagua boxing; Hong boxing.

Gaoxian: Tai chi chuan; Changjia boxing; Bagua boxing; Wudang boxing.

Yichuan: Shaolin boxing; Nanwu boxing; Tai chi chuan; Changjia boxing; Tantui; Hong boxing.

Ruyang: Shaolin boxing; Tai chi chuan; Xinyi boxing; Yi boxing (Dacheng boxing). 
Yichuan: Lin boxing; Nanwu boxing; Tai chi chuan; Cha boxing; Xinyi boxing; These make martial arts culture in Heluo area become rich and colorful.

\section{B. The Literature and Art Culture of Heluo Martial Arts}

There are many temple fairs in Heluo. In Luoyang area, over a hundred temple fairs will be held a year. Martial arts performances are concentrated in the temple fair. It forms the literature and art culture of martial arts in Heluo area, and becomes the tourism feature of Heluo area. In temple fair, various boxing school is performed, which allows more people to know the feature of folk martial arts. For example, in 2012 Heluo Culture and Tourism Festival, Nanwu boxing showed the rigid-soft combination of martial arts, causing social concern. At present, distinctive temple fairs in Heluo area include: Yiyang Lingshan temple fair, Songxian Jianggong temple fair, Luanchuan Laojunshan temple fair, Yiyang Fuchang temple fair. They have been included in provincial and municipal intangible cultural heritage list separately. It can be said that literature and art culture of Heluo martial arts has significantly promoted the spread of Heluo martial arts and the development of Heluo folk martial arts.

\section{The Significance of Heluo Martial ARts Culture IN MODERN PHYSICAL TEACHING}

\section{A. Analysis from Economic Perspective}

Economic globalization makes the political culture of different regions integrate with each other, while the cultural differences between countries are growing. The competition between different cultures will directly determine the fate of national culture in the process of economic development. [3] For the traditional culture of China, it is not only the essence of national culture, but also one of the important manifestations of our national spirit, which shows the strong cohesion and creativity of the Chinese nation. With the advent of economic integration, many people's ideas are also changing. In order to eliminate culture gap, we should transform the traditional culture into modern culture which adapts to the development of modern society. At the same time, martial arts culture also needs to keep up with this pace while not losing its own national characteristics, so as to adapt to the development of modern culture.

\section{B. Analysis from Martial Arts Perspective}

Martial arts survive in Chinese traditional culture with its own unique charm and style. In modern society, although martial arts has become a sports course, it is not the simple action learning and training that most people think. The most important thing of martial arts is its soul - martial virtue.[3] For martial arts, action is its way of expression and martial virtue is its real connotation. Usually we will learn actions of martial arts in class. Martial arts include various boxing kinds, together with different equipment and actions. People used to think that practicing these actions is only to keep fit. In fact, they have ignored the most important thing in martial arts - soul. The real soul of martial arts is that cultivate learners' artistic accomplishment through the study of martial arts. On the basis of mastering the theoretical knowledge and action skills, let them understand the implication and cultural connotation of actions. It helps to improve students' thinking skills, train their strong will and promote their all-round development.

To contemporary students, martial arts not only can help them to have a healthy body. More importantly, through the study of martial arts, students' ideological height and thinking width have been improved and expanded and their horizons have also been opened up. It helps to train students' socially living capability and adaptability, and guide students to form correct world outlook, view of life and values, and improve the overall quality of students to meet the requirements of times development[4].

\section{The Application of Heluo Martial Arts Culture IN PHYSICAL EDUCATION}

\section{A. Perfect the Teaching Mode of Martial Arts Class}

Heluo martial arts culture has been inherited and carried forward in physical education. As a course in school, physical education, namely martial arts class, must be required to have certain teaching mode and assessment system like traditional cultural courses. Generally speaking, the teaching mode is that teacher guides students and students listen to teacher's instruction and do corresponding practice according to teachers' requirement. After studying in class, constantly review what has been learned to achieve the teaching aims. And at last, test students' learning and teacher' teaching situation through assessment and scoring system. However, from the teaching situation of martial arts course in school in recent years, it can be seen that the majority of students are still resistant to martial arts course, or even hate it and think martial arts course is violent and refuse to attend martial arts class. Lack of teachers, single teaching mode, boring teaching content are the reasons that stop martial arts course from entering the school.[4] Therefore, in order to change this situation, we should pay attention to the cultivation of special martial arts teachers, increase investment, combine with modern elements, and improve the teaching mode and assessment methods, so as to improve students' interest in learning.

\section{B. Improve Martial Arts Teachers' Martial Arts Teaching Quality}

To improve the teaching quality of martial arts class, it is imperative to solve the lack of teachers. On the one hand, we need to strengthen the training of the existing martial arts teachers to improve the quality of teachers. In addition to loving students and teaching with clean hands, martial arts teachers also should have solid theoretical knowledge and a wide range of humanistic and scientific knowledge, so as to better teach students by their words and deeds. In addition, we should also increase the number of martial arts teachers. Because of the wide variety of martial arts and their own characteristics, the so-called "there is expertise involved in every profession." refers to that it is difficult for a teacher to excelled at everything, thus absorbing different types of martial arts teachers is an important way to improve the teaching quality. 


\section{Stimulate Students' Interest in Martial Arts}

"Interest is the best teacher". It is difficult for boring teaching model to improve students' interest in learning. It to a certain extent hinders the spread of martial arts culture. In order to solve this phenomenon, martial arts teachers should make improvement and innovation in the teaching methods, and aim to form good learning atmosphere and stimulate the enthusiasm of learning in student group. They should continue to try and make effort to finally achieve the protection and inheritance of martial arts culture.

\section{Arrange Pointed Teaching Materials}

Textbook is an important channel for students to learn the subject before the class. It is also an important tool to stimulate students' interest in learning. Its role is not to be underestimated. Therefore, it is an effective way to realize the combination of martial arts culture and modern teaching to arrange the content of textbook reasonably and guide students to study with purpose. There are a wide variety of martial arts. It's difficult to list them all in textbook. Therefore the textbook content should be rigorously screened and arranged to make it more targeted and scientific. At present, the martial arts textbook of lower grades is mainly simple basic martial arts actions, while the textbook content of higher grades is mainly combined actions and equipment. In addition to considering the age and mind, we should also combine with campus environment and local characteristics to achieve the combination of textbook and daily life.

\section{E. Focus on the Research of Teaching Methods}

In the teaching process of martial arts courses, teaching methods directly affect the quality and effectiveness of teaching. In the traditional martial arts class, though the teacher's leading role has been fully exploited, excessive attention will let teacher ignore the autonomy of students, and only focus on teaching and neglect whether the teaching method is worth learning or not. In order to meet the requirements of modern society and culture, exploring excellent teaching methods is the compelling obligation of teachers. Students should also change passiveness into activeness, and actively cooperate with the teaching methods of teachers, so as to progress together and achieve the inheritance of martial arts culture.

\section{F. Enhance the Status of Heluo Martial Arts with Appropriate Policy}

The development of martial arts can only enhance its education position and ensure the inheritance of martial arts culture under the support of national policy. In as early as the fourth national education session, relevant people proposed to make martial arts enter the education of each school, and also advocate taking martial arts as a national fitness activity and gradually improving the degree of emphasis of martial arts in sports competition events. The setting of country's policy has also let martial arts achieve unprecedented development. Martial arts has been included in the range of sports in some of the relevant documents. At the same time, the Ministry of Education also points out that the physical education class of some schools should appropriately add some content and knowledge of martial arts. In the process of learning martial arts, let students fully appreciate the profound traditional Chinese culture. It helps students to carry forward Chinese national spirit and pass on the national culture.

Combining with practical experience, the common teaching methods are as follows:

\section{1) Learn Classroom Etiquette}

Same as in traditional culture class, etiquette is essential in martial arts class. As the communicator of knowledge and culture, teachers are worthy of students' respect and admiration. Therefore, in martial arts class, regardless of the form of the class, teachers and students should extend greetings to each other to show respect. At the same time, emphasis and learning of the etiquette is conducive to improving the moral awareness of students and their own quality.

\section{2) Enhance Interaction and Improve the Interest of} Classroom

As mentioned earlier, in order to stimulate students' interest in learning, we should take effective teaching methods to change the boring class in the past. Some teachers will introduce game into class, which is related to but not limited to martial arts action. Students can learn actions and gain happiness and friendship in the game.

3) Focus on student development, and pay attention to the students' subject position.

At the same time, we also need to pay attention to individual differences to ensure that all students can benefit. Martial arts teaching needs to be conducted step by step. We can't be anxious for success. Teaching content, methods and load should all develop from simple to complex, from easy to difficult, from less to more, from unknown to known. They should be gradually deepened and constantly upgraded. Start with the basic skills, strengthen the practice of basic skills and basic action, and choose simple combination of single action. These can all get twofold results with half the effort when learning routines in the future.

\section{4) Hold Martial Arts Exchange}

In some physical education class, teachers often teach students martial arts knowledge only through explanation and demonstration of action. But the teaching model tends to be very boring. In view of this situation, schools can regularly hold some martial arts exchange, and enhance students' interest in learning martial arts through martial arts competition and martial arts culture exchange. In this process, students not only can examine their martial arts skills they learn in the physical education class, but also can find their own shortcomings through the exchange and know their future martial arts learning direction more clearly.

\section{CONCLUSION AND SUGGESTIONS}

One of the important reasons that martial arts is able to attract people to learn is that martial arts itself has the value of ornamental entertainment. Students can experience the beauty of martial arts through watching martial arts performances and competition process, thus having pleasant experience physically and mentally. Enjoying beauty is an innate instinct. 
People are willing to accept the beautiful things, experience it, and participate in it to get a higher level of spiritual experience. Therefore, the combination of martial arts and modern physical education can lead to resonance of students. In this process, students can feel the physical and mental experience brought by martial arts culture, and immerse themselves in the wonderful experience of martial arts culture. The combination of Heluo martial arts culture and modern physical teaching must take all the teachers and students as subject. In the campus, which is the main activity field, take the martial arts teaching as the principle thing and martial arts competition as subsidiary role, and create the martial arts culture atmosphere in constantly practice and form the campus culture phenomenon of teaching martial arts and cultivating morality. This kind of campus culture can't be separated from the support of college culture and traditional Chinese martial arts culture.

\section{REFERENCES}

[1] Qiu Pixiang. The Contemporary Significance of Martial Arts Culture and Educational Research[J]. Sports Science, 2010,2, (15): 164.

[2] Guo Shufen. inheritance and development of folk martial arts in Luoyang area from the perspective of Heluo culture[J]. Chengdu Sport University Master's Degree Thesis, 2013,5, (20): 1-31.

[3] Qiu Pixiang, The Contemporary Significance of Martial Arts Culture Research and Educational Research[J]. Sports Culture Guide, 2010,4, (30): 18-20.

[4] Zhang Yibing. The Significance of Traditional Martial Arts Culture in School Physical Teaching[J]. Fighting (Martial Arts Science), 2012,04: 25-27 + 38 . 